\title{
Natural growth as an indicator of monitoring of the linear infrastructure for safety and security issues
}

\author{
Sefer Kurnaz* \\ The Aeronautics and Space Technologies Institute Air Force Academy, \\ Turkey, \\ Rustam B. Rustamov** \\ International Astronautical Federation, Caspian Business Centre, \\ ENCOTEC, 42, J. Jabbarly street, Baku AZ 1065, Azerbaijan \\ Maral Zeynalova*** and Fazila Qasimova*** \\ Institute of Botany, Azerbaijan National Academy of Sciences, 40, \\ Patamdar Shosse, Baku AZ 1073, Azerbaijan
}

\begin{abstract}
Key words : pollution, vegetation, biodegradation, space technology, remote sensing, GIS, space image, high resolution, image processing, database, security, monitoring
\end{abstract}

\section{Introduction}

A definition of the most effective method for providing suitable and successful transportation of oil and gas through the pipelines and solution of problems related to the ecology of environment is the main requirement aspect of oil and gas safety transportation. Annually collects the statistical data which presents information on incidents as a result of intervention of the third party, ground landslides or spillage of methane. The purpose of investigations for finding out the new way of solution of problem is development of the new approach of management for the infrastructure with use of satellite monitoring system. This approach allows operators of pipelines to carry out permanent monitoring indicated of pipeline status in any weather conditions and day.

Certainly general issue of oil and gas pipeline safety includes aspects of the natural disaster and problems related to the environment.

\section{Pollution of soil by hydrocarbon raw stock and its biological activity}

Natural restoration of fertility of soil by oil pollution occurs for a long term than in case of other technogen pollution. The sharply changes of the water penetration owing to hydrofobization structural separateness are not moistened and water as though "fails" in the bottom horizons of a profile of soil; humidity decreases [1].

Oil and oil products cause practically full depression of functional activity of flora and fauna. Inhibitions an ability to live of the majority of microorganisms including them fermentation activity. Management of biodegradation processes of oil should be directed

* Director

** Coordinator

E-mail :r_rustamov@hotmail.com Tel : (+99450)3668949 Fax:(+99412)4929889 *** Senior Scientists 
firstly on activation of microbic communities, creation of optimum conditions of their existence [2]. The big heterogeneity of distribution of oil components in the soil of different areas of oilfield that depends on physical and chemical properties of concrete soil differences, quality and structure of the acted oil [3] is indicated. As a result of this condition of autopurification of an environment from toxic organic substances technogen origins in landscape zones and areas become a different [4].

The soil with the possessing property of disperse heterogeneous body operates as chromatographic a column where there is a level-by-level redistribution of components of oil. It demonstrates that oppression of plants begins when the quantity of oil hydrocarbons (HC) in soil becomes $1 \mathrm{~kg} / \mathrm{sm} 2$.

A small amount of $\mathrm{HC}$ (5 g/100 g ground) stimulates activity of microflora [5]. However process of nitrification inhibits any concentration of $\mathrm{HC}$; nitrification is the most sensitive process on "oil" pollution of soil [6]. The most important conditions of the vigorous activity of microflora at the presence of oil pollution also are humidity and temperature of soil [7].

Within the conducted investigation in a number of the oily polluted areas have been discovered satin (Stellaria media L.), quack grass (Elytrigia repens L.), cockspur (Echinochloa crusgalli L.). This stability makes a possible of using of these vegetations for side ration during the fetor cultivation.

Table 1. Influence of oil on germination of satin seeds (\% from the control)

\begin{tabular}{|c|c|c|c|c|c|c|c|}
\hline \multirow{3}{*}{ Oil Doze, \% } & \multicolumn{4}{|c|}{ Stellaria media L., \% } & \multicolumn{3}{|c|}{ Echinochloa crusgalli L., \% } \\
\hline & \multicolumn{7}{|c|}{ Days } \\
\hline & 4 & 6 & 8 & 15 & 5 & 8 & 15 \\
\hline 0 & 44 & 60 & 72 & 73 & 51 & 62 & 70 \\
\hline 1 & 38 & 47 & 56 & 59 & 42 & 48 & 61 \\
\hline 2 & 22 & 33 & 47 & 53 & 30 & 32 & 58 \\
\hline 4 & 32 & 43 & 56 & 56 & 36 & 42 & 54 \\
\hline 6 & 26 & 37 & 49 & 59 & 26 & 36 & 56 \\
\hline 8 & 19 & 40 & 46 & 50 & 24 & 38 & 50 \\
\hline 10 & 10 & 25 & 39 & 55 & 14 & 22 & 45 \\
\hline
\end{tabular}

Table 2. Growth and development of vegetative bodies of satin depending on a level of oil pollution (average statistical data is presented)

\begin{tabular}{|l|c|c|c|c|c|c|c|}
\hline \multirow{2}{*}{ Morphological Feature } & \multicolumn{7}{|c|}{ Days } \\
\cline { 2 - 8 } & 0 & 1 & 2 & 4 & 6 & 8 & 10 \\
\hline \hline The length of cone & 92,65 & 36,57 & 26,7 & 22,75 & 15,00 & 16,33 & 15,87 \\
\hline The number of leaf & 7,9 & 4,9 & 4,29 & 3,75 & 3,46 & 3,67 & 3,8 \\
\hline The length of leaf, mm & 7,8 & 3,88 & 2,36 & 2,03 & 1,64 & 1,99 & 1,84 \\
\hline $\begin{array}{l}\text { The width of average } \\
\text { leaf, mm }\end{array}$ & 6,1 & 2,95 & 1,44 & 1,2 & 0,94 & 1,08 & 1,06 \\
\hline $\begin{array}{l}\text { The length of the main } \\
\text { root, mm }\end{array}$ & 47,10 & 14,05 & 11,43 & 9,38 & 9,53 & 5,67 & 5,93 \\
\hline $\begin{array}{l}\text { Overall length of root, } \\
\text { mm }\end{array}$ & 138,5 & 49,95 & 44,70 & 26,25 & 28,87 & 27,2 & 19,4 \\
\hline $\begin{array}{l}\text { The length of lateral } \\
\text { root, mm }\end{array}$ & 9,68 & 5,8 & 5,69 & 7,88 & 5,81 & 4,24 & 4,18 \\
\hline
\end{tabular}


During the crop of seeds these vegetations in oily polluted soils shoots of a wheat grass have appeared on 3-rd, satin on 4-th and cockspur - on 5-th day (Table 1). Laboratory and field site visit investigations have been demonstrated that toxicity of the soil is in direct dependence on intensity and duration of pollution. It is revealed that the degree of inhibition of growth and development of vegetation is proportional to the oil doze. So, oil pollution rendered negative influence on germination of a wheat grass right after seeding of seeds in a soil. It explains both toxicity of the oil and acquirement by soil of waterproof properties.

The similar picture is observed with the satin seeds and cockspur (Table 2). Within 4 days satin shoots and through 5 - cockspur shoots the similar as well as a wheat grass have appeared disjointedly where then higher the concentration of oil there is a less a number of sprouts.

Inhibition actions of oil were observed at the level of pollution above then $2 \%$. An energy germination which is taken into account within 3-10 days from the date of crop in the control was equaled $100 \%$. In process of germination of seeds with increase in a doze of polluted subsistence this value decreases and at $20 \%$ pollution of soil seeds of quack grass, satin and cockspur at all did not sprout.

\section{Remote sensing as a tool of protection of the linear infrastructure}

Remote sensing technology includes as sensors of imaging and non-imaging sensors data. Remote sensing and others geospatial information technologies provide a spatial and time basis for all stages of any possible terrorist threat. To these stages would be including following phases:

Detection - new digital methods allow for the received data operative comparison spatial and temporal imaging and non-imaging information of the sensors for effective detection and analyzing of possible threat. Processing and analyzing the received information, it is possible to find out the elements of the potential threat and terrorist targets. Preparedness - personnel who involved for planning of emergency situations require current, correct geospatial information which should be in interrelation with an existing database. The up to date data of remote sensing helps schedulers in their work in planning the appropriate actions for prevention terrorist attacks, prediction, prevention and reduction of the risk action of the nature and other critical situations. Prevention - elements have been found out by means of analysis of the geospatial information provide an opportunity acceptance of the appropriate decisions for prevention of terrorist actions and attacks. Caparisoning of this information with the additional information related to the local place, for example, land cover, border of separate elements of the local place and water, and air space etc. may promote liquidation of attempts of terrorist attacks. Protection - remote sensing data in particular are very important for the analysis of vulnerability of the critical infrastructure of pipeline systems. Support technology of infrastructure for decision making as visualization of a stage and modeling of possible incident helps in protection of potential attacks and designing protective tactics and strategy. Such technologies also promote to consider of interaction of the pipeline systems with others geographically connected critical infrastructure, such as systems of water supply, settlements, power stations, railways etc. Response - efficiency of liquidation of consequences of natural disaster or human factor is possible when rapid and operative analysis of images and other acquired data received through appropriate sensors before and after disaster is carried out. Within such approach is possible to estimate a situation and make the right decision. It is necessary to note that it may promote for successful liquidation of consequences of natural disaster and also terrorist attacks as well. 
As far as it is identified that it is considered of applying of two types of examination pipelines for definition of leakages, so-called survey and patrolling. In the first case the purpose is detection of leakages in instrumented equipment. In the pipelines, classifying as a high risk the monitoring of leakage is recommended to conduct four times per year, as an average risk, two times and low risk, once a year.

The main pipelines on transportations of oil and gas are under the ground approximately with $1 \mathrm{~m}$ depth. For the zones in width of a route of $20 \mathrm{~m}$ along the pipeline following aspects should be taken into account:

- construction and ground works and excavation, imposing of cables, collectors, drainage systems and pipes, construction of buildings, under buildings, supports, etc.;

- hopper of soil, erosion, deep traces of the vehicles, flooded surfaces;

- new bushes and trees, discoloring vegetation of higher than the pipeline.

Any works carried out within the scale of $200 \mathrm{~m}$ for the both side of the pipeline should be informed and coordinated with the appropriate responsible authority person, who is the responsible for safety of the pipeline. The system of detection of leakage of gas should be capable to identification smallest dozes of gas leakage up to a stream $0.01-10$ $\mathrm{m} 3 / \mathrm{hr}$.

\section{Application of Remote Sensing Methods}

Table 3 provides a qualitative representation application of technology of remote sensing for monitoring the pipeline which is acceptable and suitable for the technical and economic point of view. It is obvious, that full monitoring pipeline system needs application of various sensors and methods of gathering of information.

LiDAR (Light Detecting and Ranging) - LiDAR - operation of this device is based on the laser radiation, working in a ultra-violet, visible or infra-red wavelength range. LiDAR systems have found the wide application in the field of ecology of the environment. Presently experimental samples of the system are installed in the helicopters for detection of the major leakages in pipelines during the transportation of oil and gas.

Thermography - the system is the optical converter of infra-red radiation to the visible spectrum range. The spectral range determining their area of spectral action there are in an interval $\lambda=3-5 \mu \mathrm{km}$ and $\lambda=8-12 \mu \mathrm{km}$ which are corresponding to the windows of transparency of the atmosphere. In case of the automated monitoring pipelines for transportation of oil and gas combination of radar and photographic systems with thermographic methods allows assessment of the image with highly accuracy and this availability will increase a probability of detection and reduce the number of the false information.

Table 3. Availability of remote sensing for oil and gas pipeline monitoring

\begin{tabular}{|l|c|c|c|}
\hline \multicolumn{1}{|c|}{ Sensor system } & Object recognition & $\begin{array}{c}\text { Leakage oil and gas } \\
\text { detection }\end{array}$ & $\begin{array}{c}\text { Earth movement } \\
\text { monitoring }\end{array}$ \\
\hline \hline LIDAR & $\mathrm{X}$ & $\mathrm{X}$ & \\
\hline Thermography & $\mathrm{X}$ & $\mathrm{Y}$ & $\mathrm{X}$ \\
\hline $\begin{array}{l}\text { High-resolution } \\
\text { optical systems }\end{array}$ & $\mathrm{Y}$ & $\mathrm{Y}$ & \\
\hline Hyperspectral sensors & $\mathrm{X}$ & & $\mathrm{X}$ \\
\hline Imaging SAR systems & $\mathrm{X}$ & & $\mathrm{X}$ \\
\hline Interferometric SAR & & & \\
\hline
\end{tabular}

$X=$ available basically, $Y=$ possible suitable 


\section{Optical Systems of the high sanction}

Optical systems of the high sanction are applicable for any platforms. For registration of the information as the digital image is using a linear photosensitive semiconductor CCD systems with quantity of elements about 12 000. Using the similar systems, adjusting them on various wavelength of spectrum it is possible of fabrication of multispectral complexes for the wide wavelength of radiation.

Presently most widely used data of the satellite, as in special as well as in commercial purposes is the IKONOS satellite. The orbit of the satellite is at height of $680 \mathrm{~km}$ from a terrestrial surface with width of a covering of the image about $1100 \mathrm{~km}$. Operation of this system basically is the within the visible spectral range that limits of implementation of monitoring when the condition of weather is not applicable for receiving of information. The fact is the work of IKONOS dependents of the condition of atmosphere.

\section{Hyperspectral Sensors}

Hyperspectral sensors measure a degree of reflection of natural and artificial objects with the high spectral resolution which allow identifying a different items existing on the surface of the ground. It is a huge elements on the surface of the ground (pigments of vegetation, minerals, rock, artificial surfaces) give the different spectra of absorption. It allows carrying out the analysis and identification of images on the basis of the collected information.

\section{Display SAR (Synthetic Radar of the Aperture) Systems}

SAR systems provide the holographic image of the local place, scanned by radar. Selecting the appropriate frequencies of spectral lengths is possible to achieve the spectral area which is transparent for the atmosphere. In this case atmospheric influences may not become a handicap for carrying out a permanent monitoring the earth a surface and detection of images. Change of resolution SAR demands of changing of the aperture and aerials of this system that limits its wide application.

\section{Interferometric SAR}

Interferometric SAR uses the phase information contained in the radar waves of two or more SAR images to develop terrain models and detect ground surface movements in the centimeter range. With tandem operation of identical SAR satellites such as the combined flights of the European ERS -1 and ERS -2 and the planned operations of Radarsat II and Radarsat III, images of the same area can be recorded with very short intervals of one day (ERS) or even only a few minutes (planned by Radarsat). As regards pipeline monitoring, this method could conceivably be used for detecting subsidence following water abstraction and the collapse of subterranean hollows or for monitoring slopes subject to slippage.

\section{Remote Sensing Data Analysis}

Investigation of the petroleum hydrocarbons on a plot and its analysis is advisable to conduct before and after the oil spill, to characterize changes in vegetative condition through time. There is an example of the oil spill accident occurred due to the third party intervention (see Fig. 1).

This area has been used for further investigations as a spilled area indicated for a long term ecological monitoring site [8]. An implementation of these studies has started from the collection of remotely sensed data from ground, airborne and satellite and the results of all information were combined.

Oil spill site has a plant canopy dominated by creosote bush (Larrea tridentata) shrub land. Qualitative field investigations indicated that upper plant canopy contact with the diesel fuel was manifest as etiolation that resulted in a grey to white color of the upper canopy and a white to slight reddening of the lower canopy graminoids and litter, partial and 


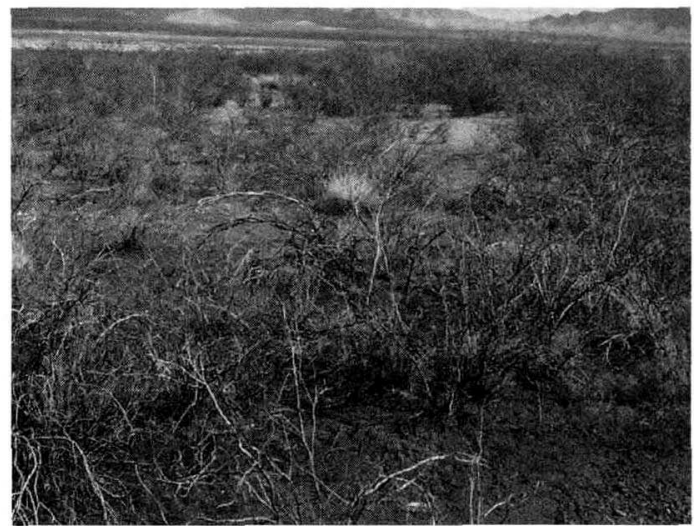

Fig. 1. Oil spilled area

complete defoliation of shrubs, apparent high mortality of much of the above ground phytomass, including grasses, cactiods and biological crusts and darkening of the orange-red alluvial soil. It was an evident that the spill boundary could be delineated on the bases of smell, as diesel was still volatizing from the soil. These features were still valuable evident one year after the release. It must be noted that the canopy dominant, creosote bush is expected to recover from the diesel spill. This aspect of plant physiology is significant for studies of resilience in desert ecosystems.

Following application of the oil, vegetation damage was assessed visually via changes in leaf color and leaf fall. There were three main time frames for injuries:

- immediate

- occurring during the initial growing season and

- cumulative, occurring after the initial growing season

Virtually all aboveground foliage that came into contact with the oil was quickly cleaned up. Turgidity was immediately reduced and foliage appeared dead within several days. The zone of contact was generally limited to the immediate areas and to areas of low relief in the pass of aboveground flowing oil [9].

In contrast, cottongrass tussock with a raised, upright growth form and species growing on areas of higher relief kept most of their aboveground biomass above the oil. These species continued to grow and flower despite their being surrounded by oil (Fig. 2).

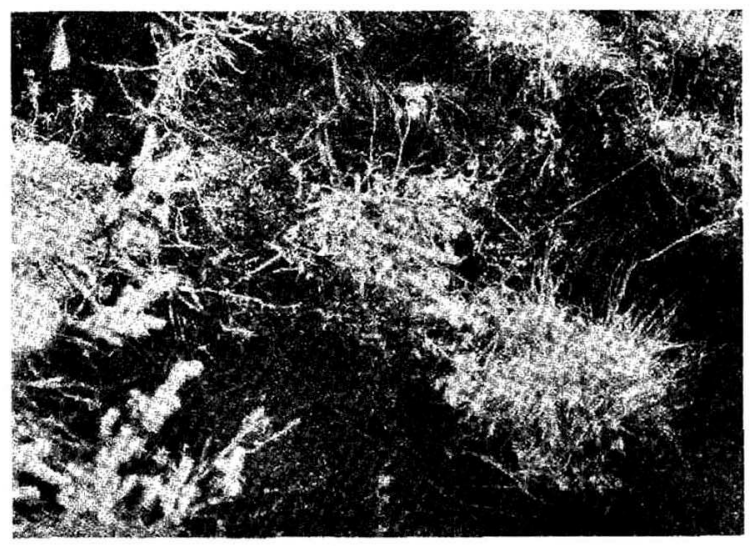

Fig. 2. Cottongrass tussock growing on spill plot despite surrounding oil 
The features of vegetation and natural growth as physical and biological parameters depends of the oil spill interaction can be used a key instrument of spectral behaviors of information within the data processing of space images for linear infrastructures.

\section{Conclusion}

The presented above results show a sensitivity of parameters of various vegetations to the influences of oil pollution. Such behavior opens an opportunity of use of those behaviors of vegetations for monitoring of the linear infrastructures as environmental indicators. These indicators significantly could be used as a key instrument within the data processing and interpretation of space images for safety and security issues of the transportations of oil and gas pipeline infrastructure.

At the time available technologies for successful implementation of issues related to the pipeline safety have been discussed. Depends of the existed huge of problems and tasks appropriate technology as well as system can be applied and carried out for these purposes.

\section{References}

1. Minbayev V.Q. The problem of land cover in petroleum production regions, Kazan, 1986 ;

2. Ismayilov N.M. Microbiological and fermentative activity of the oily contaminated soil // Restoration of the oily contaminated soil ecosystem. M., 1984;

3. Pikivskiy U.I., Solnceva N. P. Geochemical transformation of sod-podzol soil under influence of oily flow // Man-caused flow of substances of landscape and condition of ecosystem. M., 1981;

4. Glazkovskaya M.A. Autopurification ability of the environment // Priroda. 1979, No 3;

5. Slavnina T.P. Influence of the oily and oily substances to the soil properties // Melioration of the Siberian lands. Krasnoyarsk, 1984;

6. Dzienia Y.S., Westlake D.W.S. Crude oil utilization by fungi. Canad. J. Microbil, 1979. v. 24 ;

7. Harper Y.J. The effect of natural gas the growth of micro-flora. Soil Sci., 1939. v. 48;

8. David Reister, Robert Washington-Allen, and Art Stewart. Remote sensing for environmental baselining and monitoring, Final Report, DOE FEW FEAC320 Natural gas and oil technology partnership program;

9. Jenkins T.F., Jonson L.A., C.M. Collins and Mc.Fadden T.T. The physical, Chemical and Biological effects of crude oil spills on black spruce forest, interior Alaska. Arctic, v. 31, No 3 (Sept, 1978), p. 305-323. 